\title{
Covid-19: Where is the Digital Transformation, Big Data, Artificial Intelligence and Data Analytics? ${ }^{10}$
}

Fabrício Martins Mendonça, Mário Antônio Ribeiro Dantas ${ }^{1}$

${ }^{1}$ Universidade Federal de Juiz de Fora (UFJF), Juiz de Fora - MG, Brazil

Digital transformation, big data, artificial intelligence and data analytics are probably the most cited computational subjects in the news around the world. Commercial and technical reports (and papers), usually, indicate high level of success in the adoption of these approaches. In contrast, in the present war that the world is facing against Covid-19, it is not common to see many references about these technologies. In this paper, we present an ongoing research work, which observes approaches on how to effectively adopt these technologies for public primary healthcare monitoring, based on Internet of Things devices. Initial results from the proposal, which was partially funding by a public agency, indicates a differentiated approach to tackle large challenges, similar to these created by the actual Covid-19 pandemic scenario. In other words, Covid-19 required a large number of tests that could be minimized by monitoring these specific vital signals, including temperature, heartbeat rate, blood oxygen and pressure. In addition, our experiments show that the adoption of these computational topics require faster digital behavior changes and changes to the procedures from governments and people, to be successful as environments for individual health enhancement and protection.

Keywords: Covid-19, Digital Transformation, e-Health, Public Primary Healthcare.

\section{Covid-19: Onde estão a Transformação Digital, Big Data, Inteligência Artificial e Análise de Dados?}

Transformação digital, big data, inteligência artificial e análise de dados são, provavelmente, os assuntos computacionais mais citados em noticiários pelo mundo. Relatórios comerciais e técnicos (e documentos), geralmente, indicam alto nível de sucesso na adoção dessas abordagens. Em contraste, a atual guerra que o mundo enfrenta contra a Covid-19, não é

10 DOI: https://doi.org/10.21874/rsp.v71i0.4770

Submitted: May 26, 2020. Published: June 24, 2020.

ISSN: 0034-9240 | E-ISSN: 2357-8017

(c) (1) (2)

REVISTA Do SERVIÇo PúBlico | Brasília 71 (special): 212 - 234 set. 2020 
comum ver muitas referências sobre tais tecnologias. Neste artigo, apresenta-se um trabalho de pesquisa em andamento que aponta abordagens de como adotar, efetivamente, essas tecnologias para monitoramento do cuidado à saúde pública na atenção primária, com base em dispositivos Internet das Coisas. Os resultados iniciais da proposta, que foi apoiada parcialmente por um órgão do governo federal, indicam uma abordagem diferenciada para enfrentar grandes desafios, semelhantes aos criados pelo atual cenário de pandemia da Covid-19. Em outras palavras, a Covid-19 requer muitos testes que poderiam ser minimizados através de monitoração de sinais vitais específicos, incluindo temperatura, frequência cardíaca, oxigenação e pressão sanguínea. Além disso, nossos experimentos mostraram que a adoção desses tópicos computacionais exige mudanças mais rápidas no comportamento digital, nos procedimentos de governos e pessoas, para serem bem-sucedidas como ambientes de aprimoramento e proteção da saúde individual.

Palavras chave: Covid-19, Transformação Digital, e-Saúde, Saúde Pública Primária.

\section{Covid-19: Dónde están la transformación digital, Big Data, inteligencia artificial y análisis de datos?}

La transformación digital, big data, inteligencia artificial y análisis de datos son probablemente los temas computacionales más citados en las noticias de todo el mundo. Los informes comerciales y técnicos (y documentos) generalmente indican un alto nivel de éxito en la adopción de estos enfoques. En contraste, la guerra actual que enfrenta el mundo contra Covid-19, no es común ver muchas referencias sobre tales tecnologías. En este artículo, se presenta un trabajo de investigación en curso que señala enfoques sobre cómo adoptar de manera efectiva estas tecnologías para monitorear la atención de salud pública en atención primaria, basada en dispositivos Internet de las Cosas. Los resultados iniciales de la propuesta, que fue parcialmente respaldada por una agencia del gobierno federal, similar a los creados por el escenario actual de la pandemia de Covid-19. En otras palabras, Covid-19 requiere muchas pruebas que podrían minimizarse mediante el monitoreo de signos vitales específicos, incluso temperatura, frecuencia cardíaca, oxigenación y presión arterial. Además, nuestros experimentos han demostrado que la adopción de estos temas computacionales requiere cambios más rápidos en el comportamiento digital, en los procedimientos de gobiernos e individuos, para tener éxito como entornos para la mejora y protección de la salud individual.

Palabras clave: Covid-19, Transformación Digital, e-Salud, Atención primaria de salud pública. 


\section{Introduction}

The world is facing a chaotic scenario due to the new coronavirus (called SARS-CoV-2) pandemic scenario that causes the disease named as COVID-19. Currently, millions of people are infected with the new coronavirus and more than three hundred thousand have died due to COVID-19 in the world (WHO, 2020a; WHO, 2020b). However, this is not a new human chapter in this field; similar events have happened, for example, in 1918 with the influenza pandemic. In the United States, it was first identified in military personnel in spring 1918 and caused about 675,000 deaths (CDC, 2019). The main advice from health specialists to everyone is to stay at home. Moreover, all nations, include all those coined as first world (NATIONS ONLINE, 2005), are facing the same scenario of many infected people and lack of resources to avoid and treat this Covid-19 pandemic.

The new coronavirus pandemic exposed not only fragility in the health infrastructure of many countries, but also a lack of accurate information for decision-making processes at the level of public management, at the logistical and operational level and at the level of supporting healthcare professionals in clinical decisions and diagnosis. In other words, it is possible to infer that the health digital transformation has not occured around the world as it was expected to. Digital transformation is understood as the change process carried out through the use of socalled social, mobile, analytical and cloud technologies, which significantly affect three or more dimensions: at the individual, business and/or social level (TOOLBOM, 2016). These types of technology are recognized as those capable of generating business innovations affecting social and economic life (BHARADWAJ et al., 2013; FITZGERALD et al., 2013).

Digital transformation is not a new issue and, in recent years, has been a central theme in several sectors of society, including business, economics and health. Digital transformation and Industry 4.0 were the themes of the 2016 World Economic Forum in Davos (WORLD ECONOMIC FORUM, 2016). Santos and Massó (2016) affirm that digital transformation must be a priority on our agendas and on the agenda of any country, simultaneously with adapting to the competitiveness that today's world naturally demands of us. Zarzalejos (2016) corroborates this thought, stating that the degree of joint modernization of a country, its society and its productive system is based on its degree of digitalization.

Besides the health concerns and very tightly coupled to this problem, the challenge to keep people and economies in an appropriated synchronism is especially hard. The IMF states that: to help lay the foundations for a strong recovery, our policy advice will need to adapt to evolving realities (IMF, 2020). It is important to have a better understanding of the specific challenges, risks 
and tradeoffs facing every country as they gradually restart their economies. How can IMF advise without any health digital data for proper analytics research?

Big data has several definitions and views. As is mentioned by ORACLE (2020), to truly understand big data, it is helpful to have some historical background. Gartner's definition, circa 2001 (which is still the go-to definition) states that: Big data is data that contains greater variety arriving in increasing volumes and with ever-higher velocity. In addition, Gartner's definition states that big data includes larger, more complex data sets, especially from new data sources. These data sets are so voluminous that traditional data processing software cannot manage them, but these massive volumes of data can be used to address business problems not possible to tackle before.

Google mentioned that it brings the benefits of Artificial Intelligence (Al) to everyone, with the Google Al - set of Al products and solutions. Google Al conducting research that advances the state-of-the-art in the field, applying Al to products and to new domains, and developing tools to ensure that everyone can access AI (GOOGLE 2020).

The definition of data analytics could be understood as shown in SAS (2020): analytics using data and math to answer business questions, discover relationships, predict unknown outcomes and automate decisions. This diverse field of computer science is used to find meaningful patterns in data and uncover new knowledge based on applied mathematics, statistics, predictive modeling and machine learning techniques.

Based on reports from WHO (WHO, 2020a; WHO, 2020b), the actual challenge of Covid19 is similar in most countries under the computation framework. Therefore, it is important to have a larger discussion on how digital transformation, big data, artificial intelligence and data analytics could be more useful and effective in the future to mitigate this type of pandemic. In other words, how technologies could be key elements for health enhancement and protection of individuals.

In this paper, we present ongoing research to public primary healthcare. The main research question for our contribution is how to gather digital data and treat large amounts of digital data, utilizing off-the-self smart bands and tools for public primary healthcare monitoring, providing an auxiliary tool to control Covid-19. The Covid-19 required many continuous tests, which were not feasible. This research minimizes these numbers by monitoring specific vital signals (e.g. temperature, blood oxygen and pressure and heartbeat rate) through digital data captured from off-the-shelf smart bands and provided to public primary healthcare professionals.

The present research comprises two main phases. In the first phase (completed) a computational architecture is presented, based on a Fog and Internet of Things (IoT) approach, 
to support public primary healthcare with monitoring of vital signs of volunteer individuals through smart bands and software for this purpose. This phase was financed by a public agency ${ }^{75}$.

The second phase of the research (in progress) corresponds to the use of the architecture proposed in the previous stage, its hardware devices, software and experimental results in the current pandemic context of COVID-19. In order to expand the results of the research in the context of health care in times of a pandemic, this phase

was submitted to a federal government agency with a total project cost of US\$70.000. Part of that amount will be used for the acquisition of 100 smart bands for monitoring patients from the public primary health care network in the regional public hospital of the city of Juiz de Fora, included patients diagnosed with COVID-19 and others patients. The results obtained in the regional hospital and in the health public network of Juiz de Fora can be expanded and replicated to the entire primary public healthcare. In other words, representing a monitoring approach could save lives and bring more security information inside environments to those who are required to work during the COVID-19 pandemic.

The paper is organized as follows. In section II, we present some aspects related to digital transformation, big data, artificial intelligence and data analytics in e-health. Section III shows related work and describes the proposed architecture to support a public primary healthcare approach. Section IV shows preliminary experimental results. Section VI presents conclusions and future work.

\section{Digital Transformation, Big Data, Artificial Intelligence and Data Analytics}

In this section, we present some concepts related to digital transformation, big data, artificial intelligence and data analytics related to e-health. Because of the large variety of areas and environments inside e-health, we selected some segments potentially relevant to the present challenge of the Covid-19 pandemic.

\subsection{Digital Transformation}

While the concept of "digital transformation" and its practical management is a concern in parts of the business environment, including large companies like Google, Amazon, Apple, NetFlix, among others, the use of technologies that promote digital transformation still is done reluctantly in the field of public health in Brazil and in many countries, including those considered "developed" or first world.

\footnotetext{
${ }^{75}$ The Fog-IoT approach partially funded by TBE and EDP under supervision of ANEEL - The Brazilian Regulatory
} Agency of Electricity Project number PD-02651-0013/2017. 
As is discussed in Tardieu et al (2020), health care is facing the challenge of affordability in a growing and aging population. The authors argue that progress in data-enabled precision medicine is beginning to transform traditional linear models to an environment of multi-sided market variants. In this scenario, healthcare providers (such as hospitals, pharmaceutical companies, doctors), on the one side, and healthcare payers (governments, insurance companies, patients) on the other require a balance between the best possible health outcomes and cost. Tardieu et al also observe that future healthcare affordability, patient experience, treatment efficacy, healthcare capacity and system efficiency will depend on the success of health information exchange platforms and leveraging of electronic health records.

In the health area, technologies related to Telemedicine contribute to digital transformation. Technologies used for telemedicine have been available for decades (ROCHA et al., 2016; KESSARA, JONAS and SCHULMAN 2020); however, high costs combined with the impossibility of high-speed internet access limited its possibilities for expansion until a few decades ago. Currently, the evolution of hardware and software components and network capabilities have made the application of telemedicine extremely viable. Even so, its use comes up against many obstacles in the scope of health, such as: i) heavy regulation and lack of consistent investments (FLANNERY and JARRIN, 2018); ii) strict data protection and privacy regulations (PRICE WATERHOUSE HEALTH RESEARCH INSTITUTE, 2020); iii) restricted use of telemedicine services in rural or remote areas (KESSARA, JONAS and SCHULMAN, 2020); and iv) the legacy of healthcare models historically structured in personal interactions between doctors and patients (KESSARA, JONAS and SCHULMAN, 2020).

These same obstacles are some of the reasons that currently prevent further advances in the adoption of technologies for digital transformation in the health field. However, this situation has begun to change, given the urgency of measures and transformative actions to combat the pandemic of the new coronavirus. A good example of this occurred in the United States with the approval of Public Law no. 116-123, which now allows the use of telemedicine services for all beneficiaries of the Medicare health insurance system with a service fee (KESSARA, JONAS and SCHULMAN, 2020). A similar measure was adopted in Brazil, through Law no. 13.989. which authorizes the use of telemedicine, on an emergency basis, for the duration of the crisis caused by the coronavirus (SARS-CoV-2), with public authorities paying for the telemedicine services offered by SUS (BRASIL, 2020).

The work presented in Ricciardi et al (2019) provides an interesting view on how to govern the digital transformation of health services. The authors mention that, similar to other innovations and (new) technologies, such promises could or could not materialize and provide potential 
benefits. In addition, it also highlights that some technologies may also be accompanied by unintended and/or negative (side) effects in the short or long term. As a result, observed by the authors, the introduction, implementation, utilization and funding of digital health technologies should be carefully evaluated and monitored. Ricciardi et al (2019) draw attention to the importance of governments playing a more active role in the further optimization of both the process of decision making (both at the central and decentral level) and of the related outcomes. Authors also argue that governments need to find a balance between centralized and decentralized activity. Moreover, the health care system needs to be more broadly prepared to be able to transition to digitalization. It is mentioned that the threshold of what is important rises from education, through financial and regulatory preconditions, to implementation of monitoring systems to monitor its effects on health system performance.

\subsection{Big Data}

The sensing of environmental signals both the home and the people, as it shown in Figure 1 from research work presented in Silva, Gonçalves and Dantas (2019). This figure provides an example, which we developed for an e-health proposal, which results in a large amount of useful data from the home and mainly from the people inside.

Audio/video uploads and file transfers are used, respectively, to simulate the teleconsulting service and send medical images. In the application that we developed previously (SILVA, GONÇALVES and DANTAS, 2019), called QoCManApp, the sensed data are collected, quantified and evaluated, ensuring that only qualified context objects are distributed. Whenever a new data entry is detected in the KB, the inference engine interprets the rules to check for QoE (Quality of Experience) degradation (in this step, the QoC - Quality of Context - parameters associated with the context are analyzed); if there is degradation, the sensed data are discarded. Semantic processing ensures that only accurate, current, valid, complete and significant data are sent to the remote service center. 
Figure 1. Ambient Assisted Living example (SILVA, GONÇALVES and DANTAS, 2019)

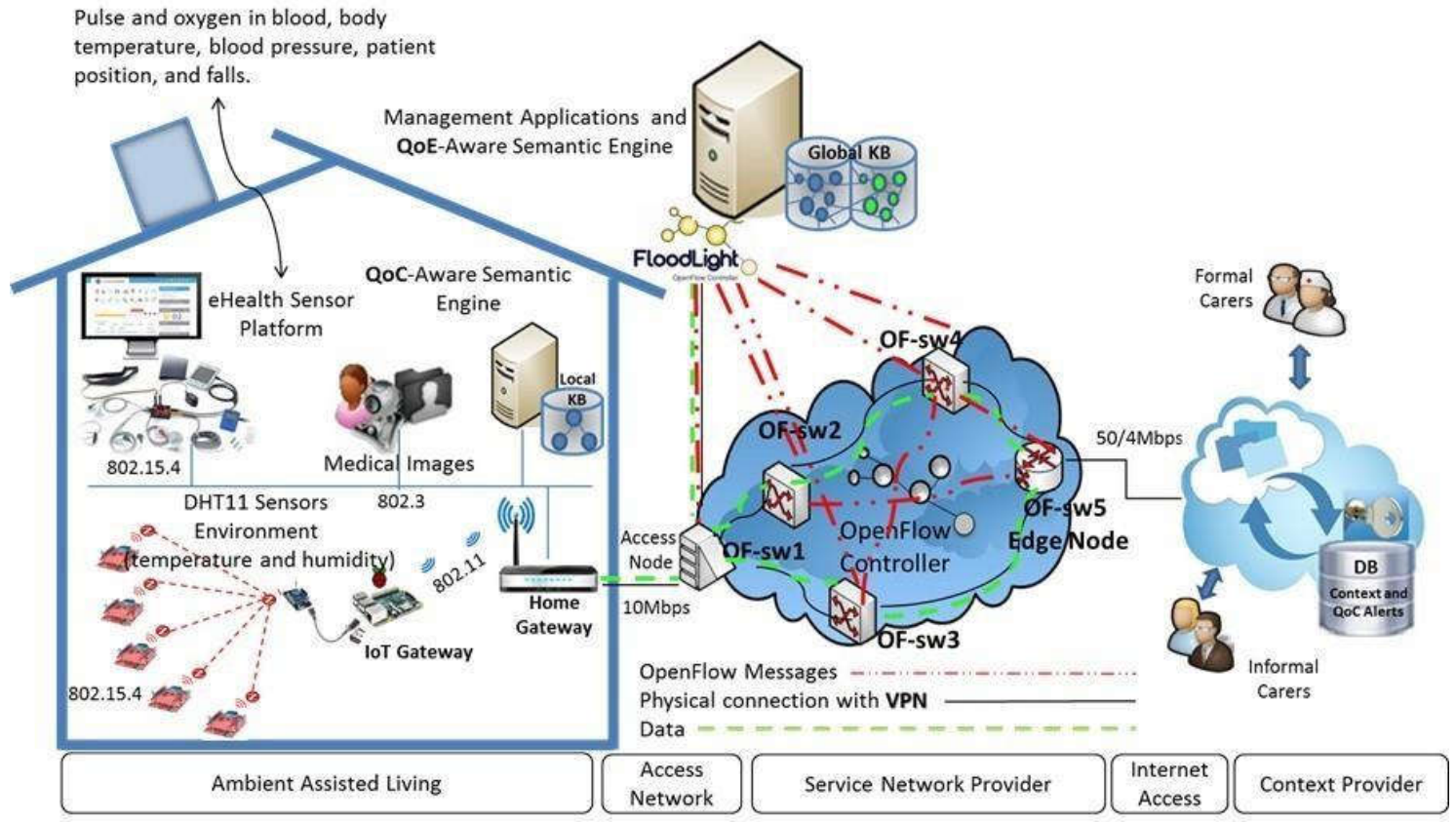

Source: Elaborated by the authors

This research work example was chosen because it is an objectively interesting effort which generates a large amount of e-health big data, without exposing people and health professionals. Libelium Cooking Hacks (2014) presented as an interesting e-health sensor environment that could help those planning on to building an environment to data collect in similar scenario. On the other hand, an approach for analysis of QoS requirements for e-health services and mapping to evolved packet system QoS classes is presented in Skorin-Kapov and Matijasevic (2020).

\subsection{Artificial Intelligence}

As Impedovo and Pirlo (2019) mention, artificial intelligence is changing the healthcare industry from many perspectives, including diagnosis, treatment and follow-up. A wide range of techniques has been proposed in the literature, such as applications of Al in health care; knowledge; data mining and knowledge discovery in medicine; medical expert systems; personal medical feature data; medical device technologies; diagnoses and therapy support systems; machine learning-based medical systems; and pattern recognition in medicine.

In addition, Cremer and Loebbeck (2019) state that in an era of accelerating digitization and advanced big data analytics, harnessing quality data and insights will enable innovative research methods and management approaches. Among others, artificial intelligence imagery 
analysis has recently emerged as a new method for analyzing the content of large amounts of pictorial data. Their research work contribution provides background information and outlines the application of artificial intelligence imagery analysis for analyzing the content of large amounts of pictorial data.

Both references (IMPEDOVO and PIRLO, 2019; CREMER and LOEBBECK, 2019) provide clear ideas about the Al tools and proposals that require appropriated data. In other words, there is an assumption that the data is clean and sanitized. The research work presented in Tae el al (2019) mention that the wide use of machine learning is fundamentally changing the software development paradigm (coined as Software 2.0) where data becomes a first-class citizen. However, it is time to extend the notion of data cleaning for modern machine learning requirements.

\subsection{Data Analytics}

Raghupathi and Raghupathi (2014) reaffirm that big data analytics has the potential to transform the way healthcare providers use sophisticated technologies. The authors mention that it is possible to have some improvements from their clinical and other data repositories and have enhancement decisions. However, they also comment that in the future, we will see the rapid, widespread implementation and use of big data analytics across the healthcare organization and the healthcare industry.

In addition, several challenges are highlighted that must be addressed. The authors also observe that big data analytics and applications in healthcare are at initial stage of development, but advances in platforms and tools may accelerate their maturing process.

\section{Related Work and Proposed Architecture}

The previous section clearly let us infer that in order to differentially tackle the challenge of digital healthcare transformation, the adoption of new technologies must be carefully employed. Therefore, this section represents the first step of this paper contribution, because it highlights how we can conceive a modern architecture design to support a public primary healthcare monitoring.

The research challenge from our project is to provide, through a distributed monitoring approach, digital data from individuals to those responsible for public primary healthcare. In the Covid-19 pandemic, the contribution focus is in providing vital signals monitoring to provide some indications from a person contamination (e.g. changes from temperature, oxygen level and blood 
pressure). This is a differential approach, because it can avoid a continuous massive test in the present scenario of billions of people.

The approach mentioned was the ordinary idea of cloud computing facilities and infrastructure. Therefore, we present some recent efforts found in the literature (e.g. BIERZYNSKI et al, 2017; DU et al, 2018; XIAO and KRUNZ 2017) related to fog-cloud environment cooperation. This cooperation is a vital element inside an architecture to collect and gather large amounts of digital data.

Bierzynski et al (2017) present the cooperation between the fog and the cloud in mobile cloud computing environments. The authors claim that this configuration could offer improved offloading services to smart mobile user equipment (UE) with computation intensive tasks. This paper tackles the computation offloading problem in a mixed fog-cloud system by jointly optimizing the offloading decisions and the allocation of computation resource transmit power and radio bandwidth, while guaranteeing user fairness and maximum tolerable delay.

Alternatively, a study on the workload offloading problem to fog computing networks is presented in Du et al (2018). This work suggests that a set of fog nodes can offload part (or all) of the workload originally targeted to the cloud data centers to further improve the quality-ofexperience (QoE) of users. Authors also investigate two performance metrics for fog computing networks: users' QoE and fog nodes' power efficiency.

Research presented in Xiao and Krunz (2017) mentioned that traditional cloud-based infrastructures are not enough for the current demands of Internet of Things (loT) applications. The authors claim that two major issues are the limitations of latency and network bandwidth. In addition, the authors call to attention that in recent years, the concepts of fog computing and edge computing were proposed to alleviate these limitations by moving data processing capabilities closer to the network edge. They also mention that considering loT growth and development forecasts for the full potential of loT can, in many cases, only be achieved by combining cloud, fog and edge computing. The authors also highlight developments and possibilities as well as consider challenges for implementation in the areas of hardware, machine learning, security, privacy and communication.

One important aspect to be observed is changing from classical cloud architecture to present research proposals, as illustrated by Figure 2. In a new fashion cloud configuration, applications represented in Figure 2 may not be supported. Reasons for this obsolescence include the high volume of data and latencies related to the communications links. On the other hand, the figure demonstrates the conventional services at cloud infrastructures (laaS, PaaS, SaaS), where clients are only passive elements. 
Figure 2. An ordinary view of a cloud connection

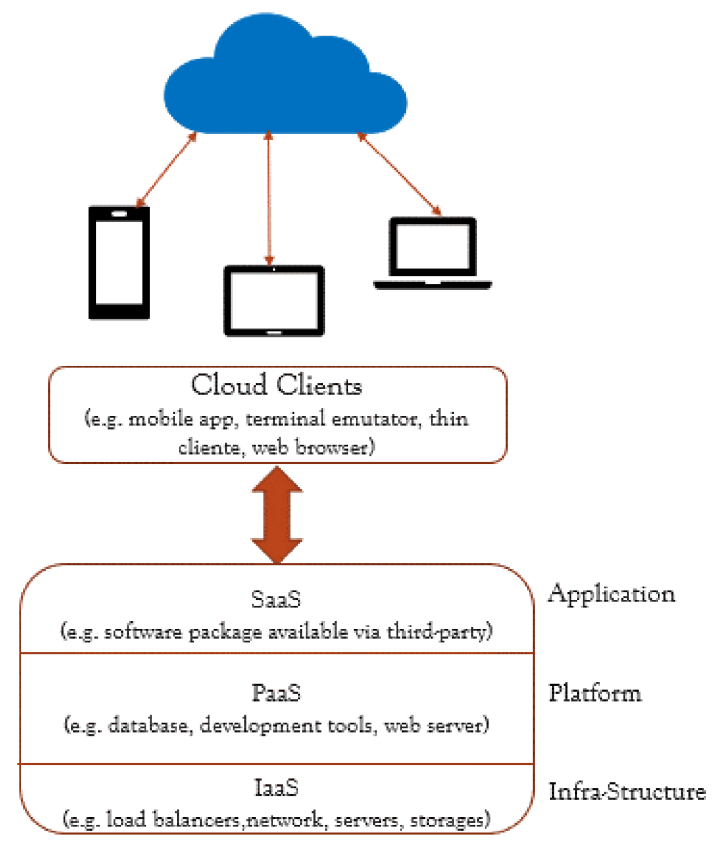

Source: Elaborated by the authors

Figure 3 illustrates a successfully adopted new paradigm (from our previous research) to connect local devices through a fog environment and then to a cloud infrastructure (DANTAS, BOGONI and FILHO, 2020). Advantages of this approach include capture of personal distributed data health, potential for local storage, potential for use in local AI applications, local data cleaning and ability to gather several data sources and then submit to the cloud. These attributes enhance the quality of data that will be uploaded to the cloud, therefore providing a more accurate information about the edge points in the fog environment. 
Figure 3. Proposed fog-cloud infrastructure

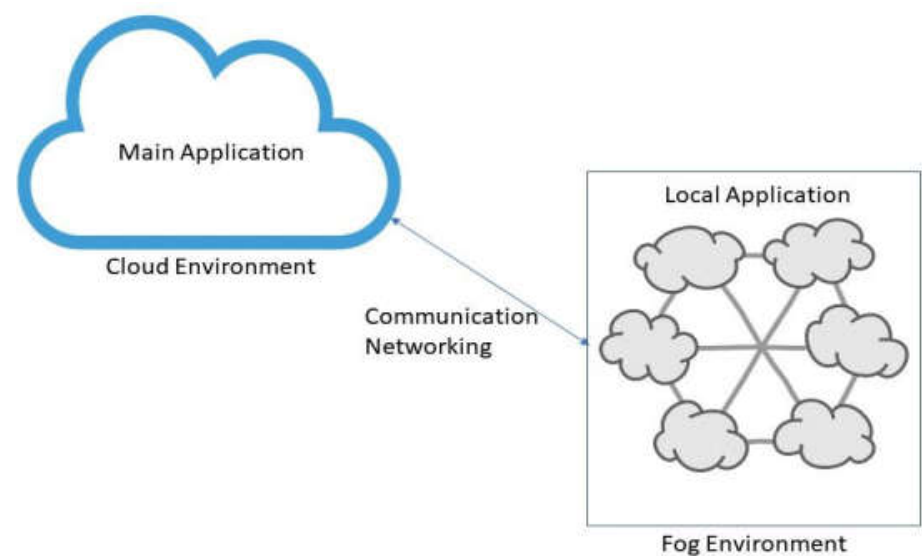

Source: Elaborated by the authors

After choosing which type of communication network paradigm was the most appropriate infrastructure, the public primary health care architecture conceived is presented in figure 4. It is relevant to mention that our case study efforts started because of a Federal Brazilian Government proposal call targeting public services polices. Therefore, our proposal is oriented to public services.

Figure 4. The public primary health care architecture

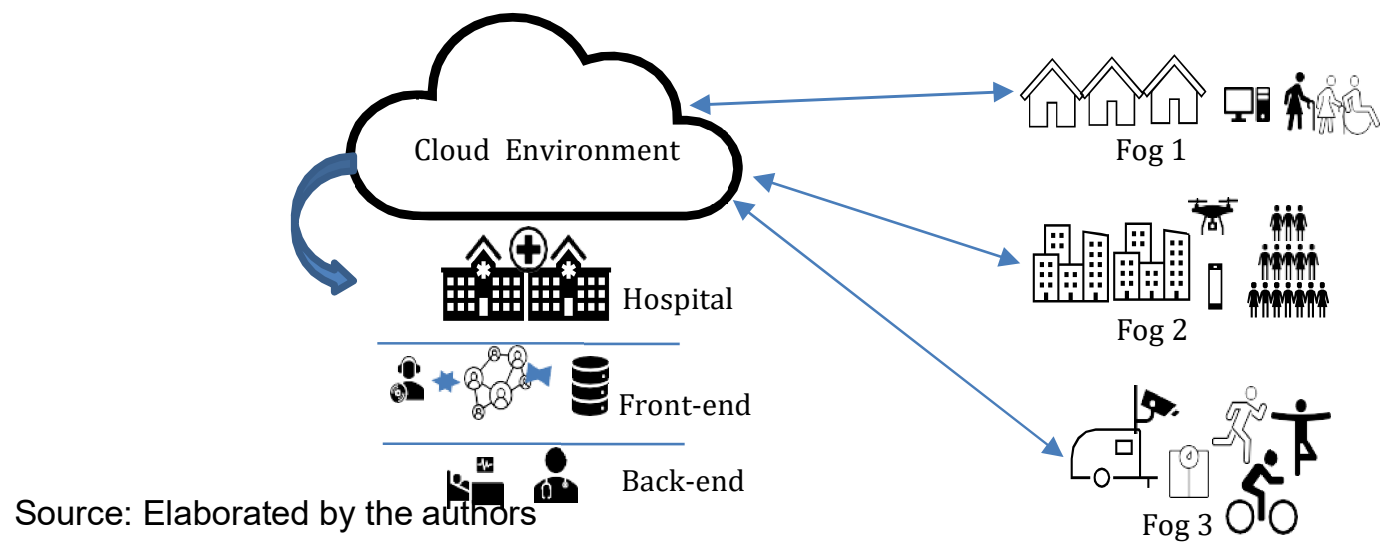

In the architecture, we have three different type of fog environments:

- Fog 1: in this group we considered elderly people and people with disabilities. In addition, local computer and mobile facilities were considered.

- Fog 2: this second group was a group from poor communities (or slums). This group included people with different age, sex and health conditions. 
- Fog 3: this group focused on persons with a history of regular exercise and sport practice.

One of the main reasons for these different groups of fog classification is based scientific observation from previous research works, such as those presented in Nazario et al (2017). When an appropriated environment is designed with the peer actors, the effort to evaluate quality of context is minimized. In other words, we effectuated an important preprocessing action for an assistant's front-end inside the hospital.

The next stage was to design how the data gathered from the fogs would be received and treated inside the hospital structure. Therefore, understanding the local procedure from a public hospital we called one stage front-end and another back-end. Similar to computer science jargon, the first element receives and preprocess the received data. The second level, coined as backend, is the location for a doctor responsible for central monitoring.

As was mentioned in literature previously presented (TARDIEU et al, 2020; RICCIARDI et al, 2019), the conceived public primary healthcare environment could, for example, provide the following attributes:

- A balance between the best possible health provisions and cost. Due to fact that gathering digital data could enhance the initial process by facilitating the best choices of assignments and avoiding unnecessary costs with medical care professionals and facilities.

- The fresh digital data gathered from users would represent an up-to-date figure of the outside scenarios, from the fogs.

- This innovation with new technologies could materialize potential benefits of data storage for future differential data analytics, utilizing new Al software packages.

\section{Experimental Results}

In this section, initial experimental results from our ongoing project are presented. Therefore, we are going to present four pieces of the architecture. Fog environments are the first three, followed by the fourth scenario representing the real public hospital. This choice was based upon the level of technology familiarity from persons involved in the experiments. 


\subsection{Scenario Fog 3}

In this space people that exercise regularly and athletes were the population of the fog. They commonly utilized commercial devices to monitor their physical activities. Therefore, we considered their own smart bands as a device to collect their data. Figure 5 illustrates, from a smart band Fitbit Alta, some snapshots with parameters such as distance, active minutes and sleep.

We have noticed during the experiments that some of those devices do not allow for open data access. These devices have several facilities, however, gathering data from an outside application is not easy and sometimes could not be realized. Another point observed was the complexity of using some functions, due to the large amount of options or required knowledge of the device.

Figure 5. Some snapshots from an ordinary smart band in Fog 3.
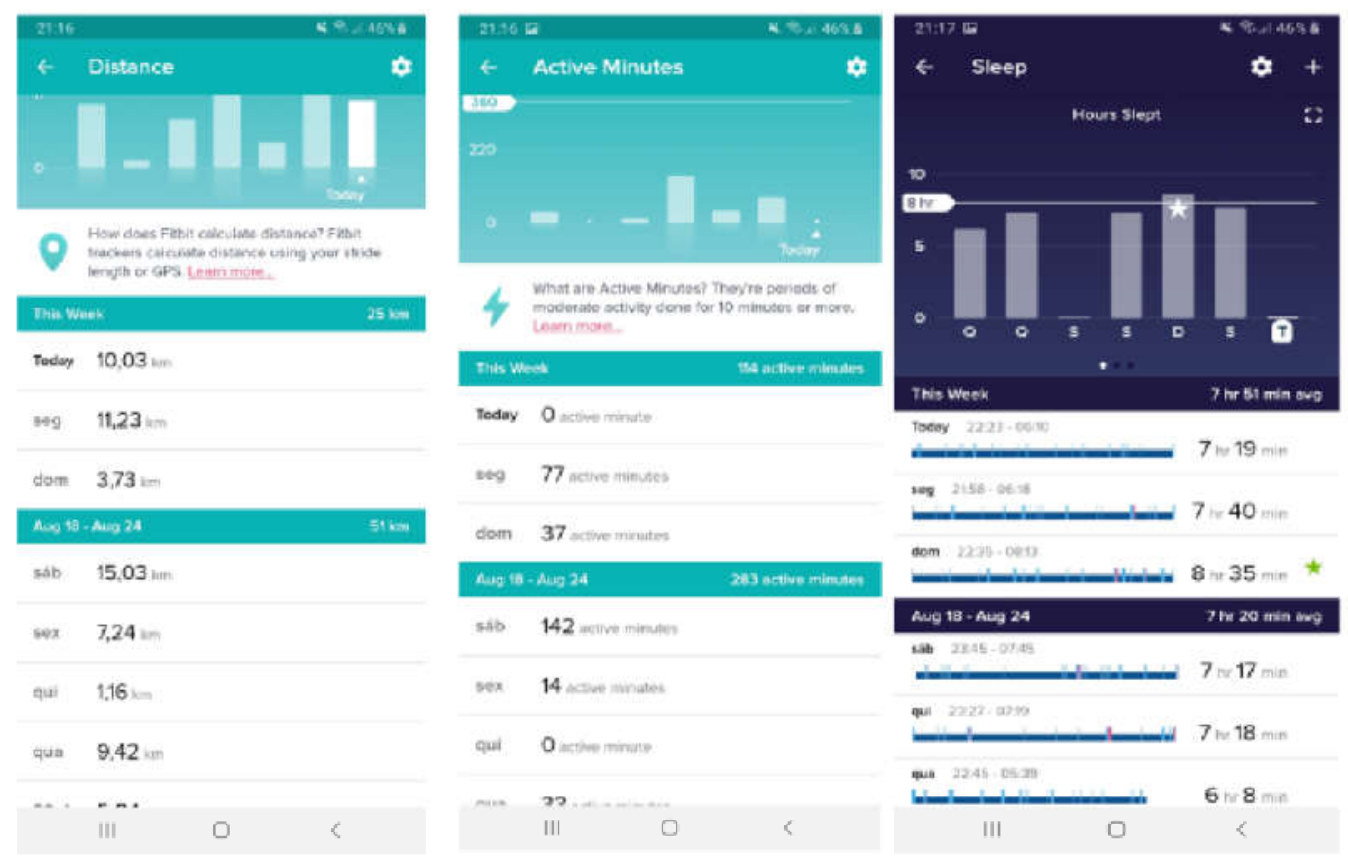

Source: Elaborated by the authors

\subsection{Scenario Fog 2}

In the Fog 2 we considered a population from a slum, where devices that are complex to setup and expensive are not realistic to use. Therefore, we performed a search for the cheapest smart band which could fulfill our requirements for simplicity and open digital data. The devices bought for the experiments were Kaihai IP68, which each cost US\$25. This device presented 
some similarities to the first set of devices, from Fog 3, as Figure 6 shows. On the other hand, they could provide an easier way to gather the personal data as an open data source for public effort.

Figure 6. Heartbeat, blood pressure and blood oxygen from Kaihai IP68

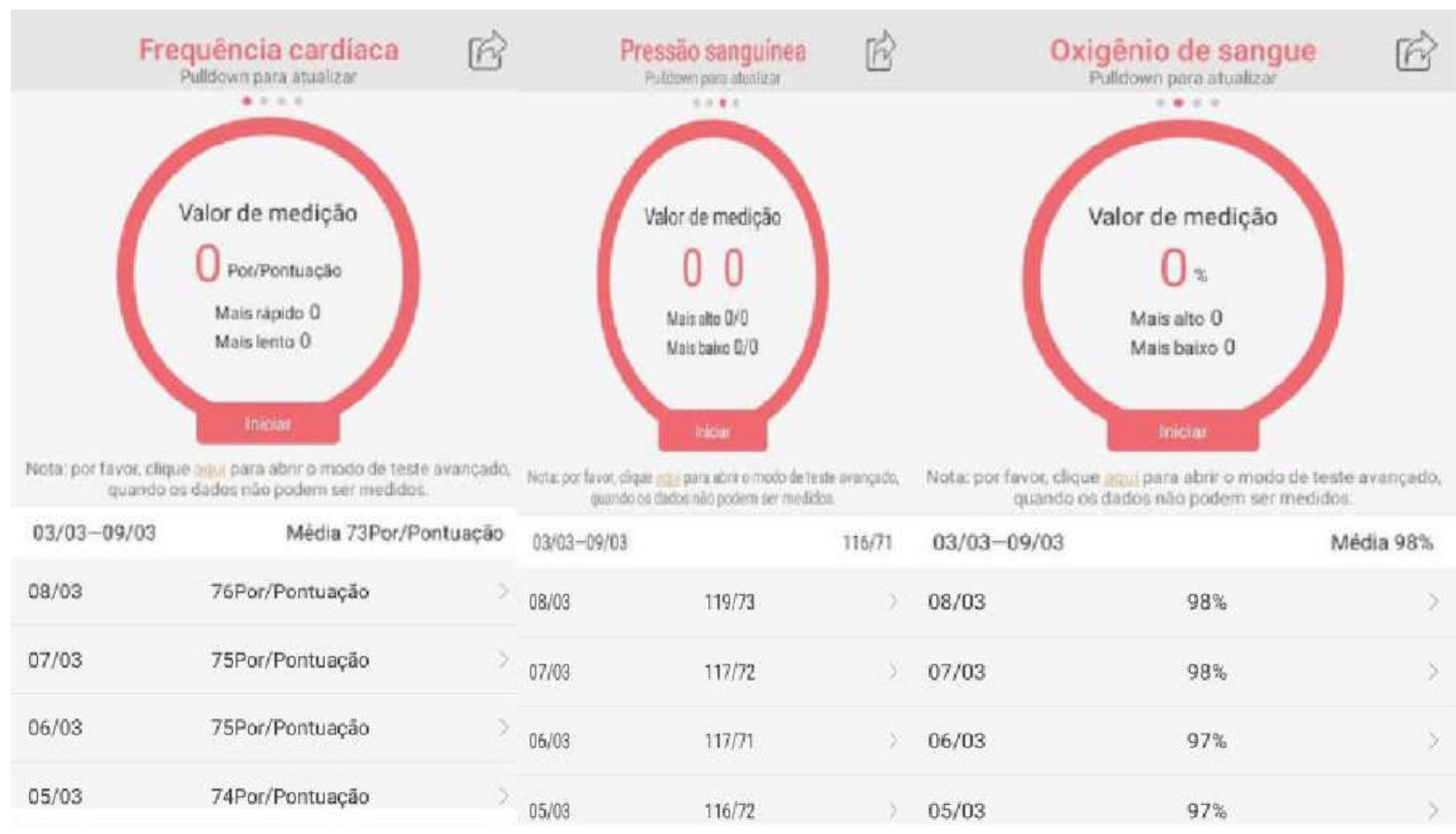

Source: Elaborated by the authors

\subsection{Scenario Fog 1}

Due to the characteristics from the people inside this fog group, we decided to develop an app, called the loT App. The goal was to have the loT App in the mobile phone which could help in the capture of vital signal data and to execute their synchronizations. Vital signals (e.g. temperature, heartbeat, oxygen and blood pressure) are essential to monitoring people and indicating some indications of Covid-19 signals. Figure 7 illustrated an example from a screenshot of the application. Important to mention is that monitoring vital signals in the Covid-19 pandemic could represent a differentiated support tool, avoiding a large number of unnecessary tests. This application are in the stage of testing, because challenges were discovered during the tests with some smart band devices and we are still developing it. 
Figure 7. Mobile phone loT APP facilities

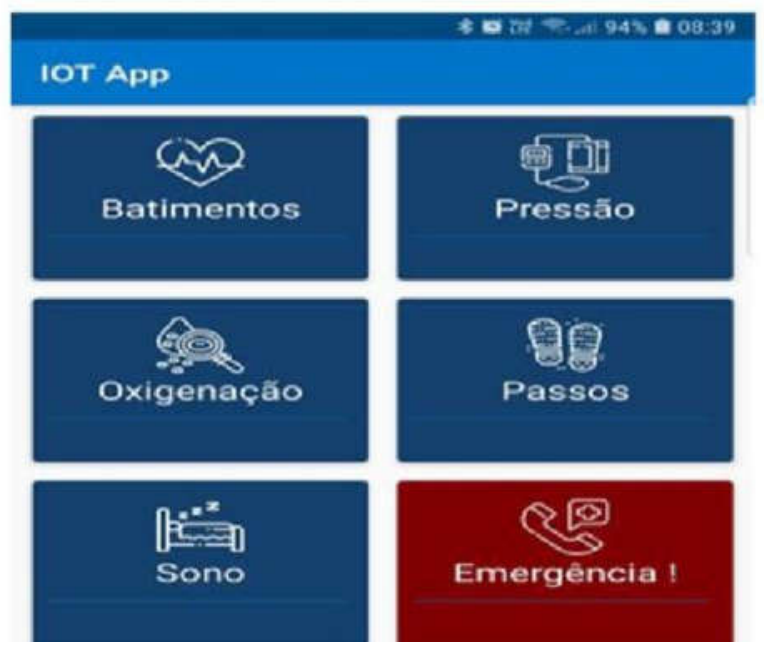

Source: Elaborated by the authors

\subsection{Scenario Hospital}

The final scenario was the public hospital, which will be the healthcare providers (TARDIEU et al, 2020). The partner for the research was a public hospital in the city of Juiz de Fora, in Brazil, which clearly understood the goal and benefits from e-health digital data. This public hospital is a regional reference for the care of patients in the mesoregion of the Zona da Mata of the state of Minas Gerais with a current capacity of $50 \mathrm{ICU}$ beds and 129 infirmary beds, with both able to receive patients diagnosed with Covid- 19 .

The experimental development of a front-end and a back-end in parallel with the hospital software application is presented in the following figures. Important to mention is that this is an ongoing project with a highly-coupled cooperation between the two parts (the federal university and the public hospital).

Figures 8 and 9 show interfaces of the monitoring web system for data collected from patients, which functions as a monitoring center composed of a coordinator doctor and a team of nurses and health agents. Figure 8 shows how the coordinator doctor usually acts in the hospital software package. The collaboration allows for the gathering of the experimental digital data from our fogs. In Figure 9, it is possible to visualize a screen shot with the temperature and heartbeat from a patient, who could be a hundred kilometers from the hospital. Through this system, it is possible to consult patient data, including data from the electronic medical record (for example, history of consultations and administered drugs), parameters collected from the devices (for example, body temperature and heart rate) and patient historical series. From the analysis of the 
collected data, this system allows intervention actions by the monitoring center, which range from an online assessment with the patient to the dispatch of a medical team to the patient's residence for emergency care.

Figure 8. An interface for the coordinator doctor

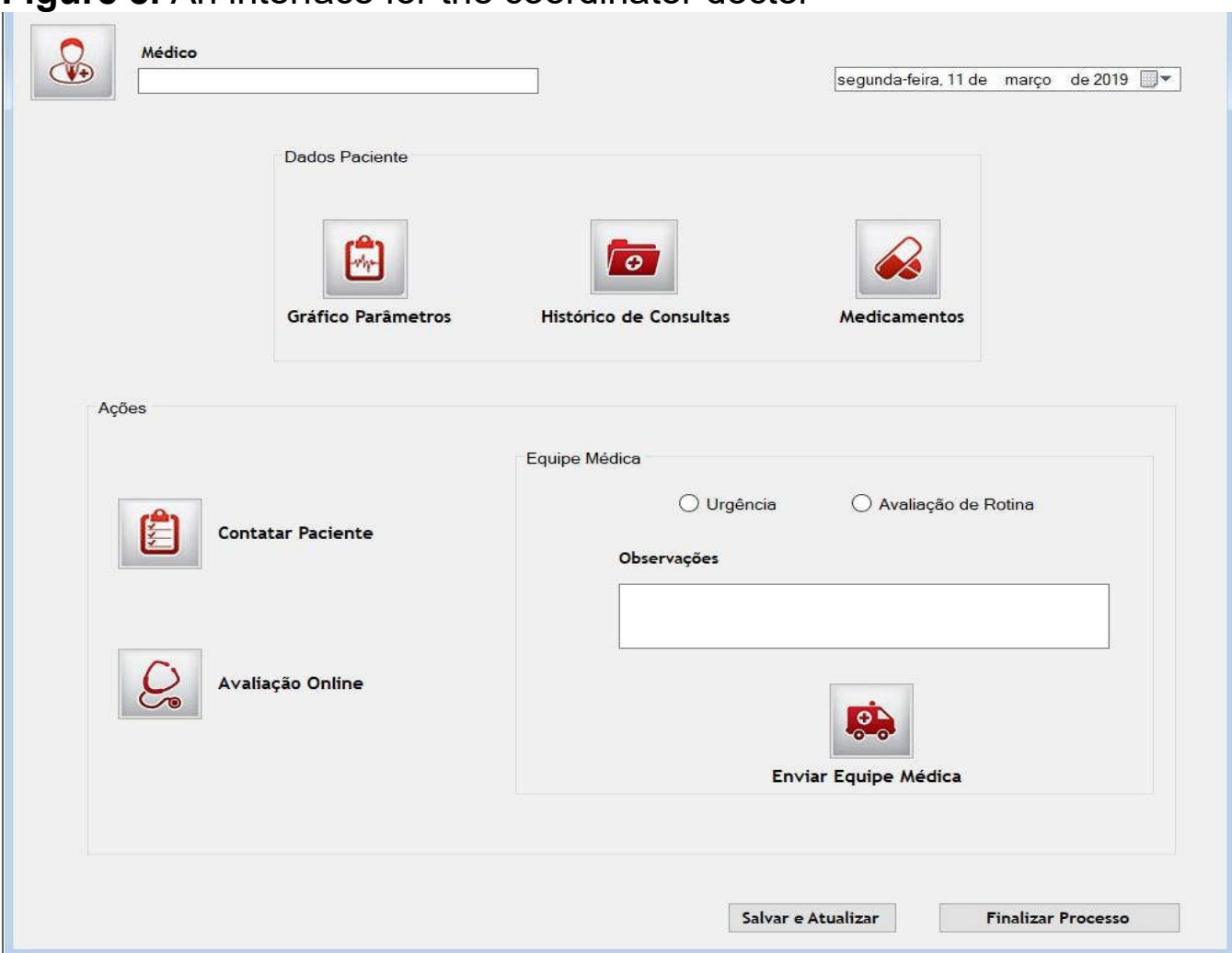


Figure 9. An interface example of patient temperature and heartbeat

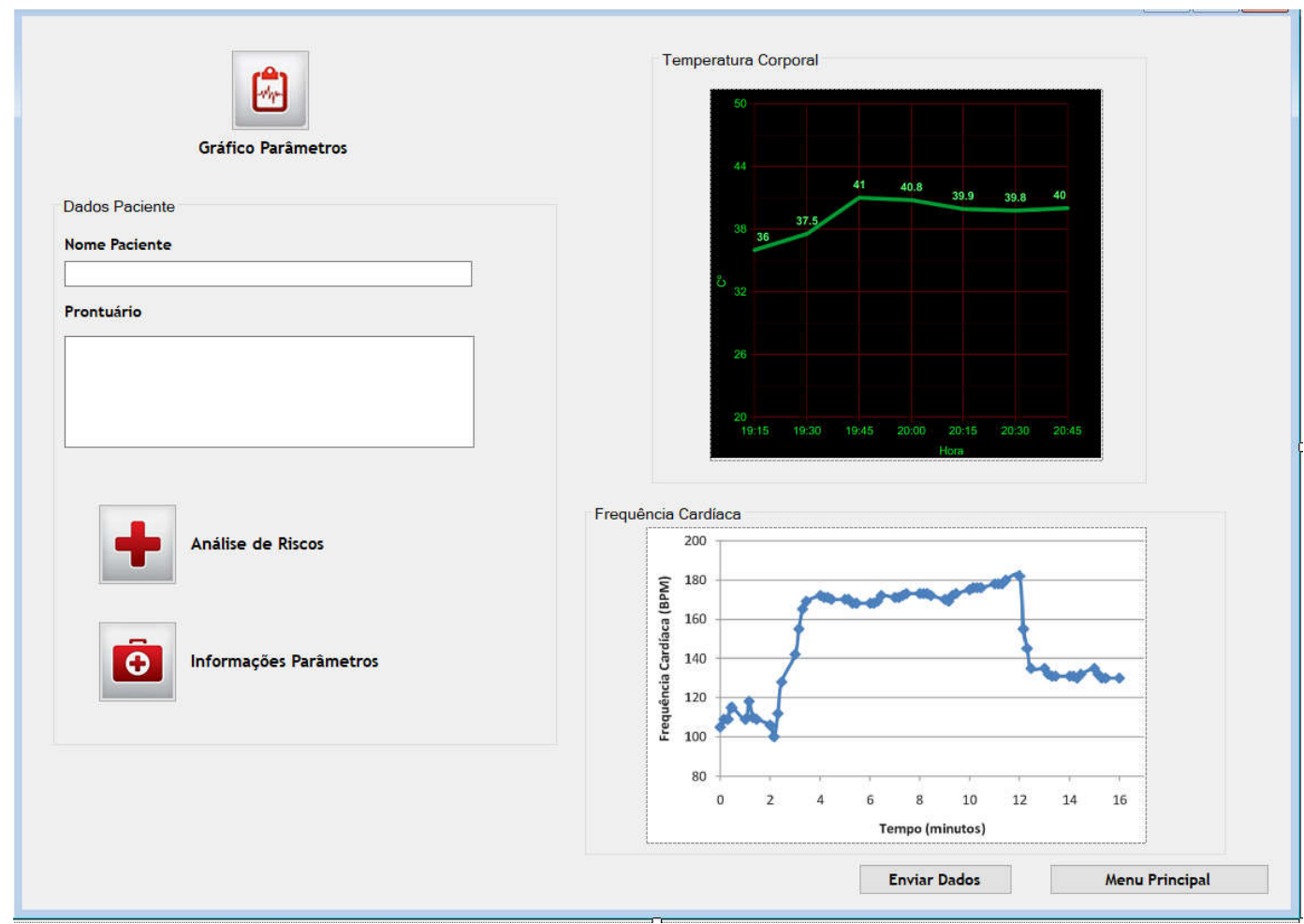

After a medical intervention action is triggered by the monitoring center, the next step in the care workflow is performed by the health agent at the patient's home. Using a mobile application developed (see Figure 10), the health agent records the information from the service (medications, medical records, observation and the patient's pain scale - Visual Analogue Scale - VAS) and also ends the service, registering one of the 3 (three) possible states: death, on-site care or referral for hospitalization. 
Figure 10. An interface for the health agent at the patient's home
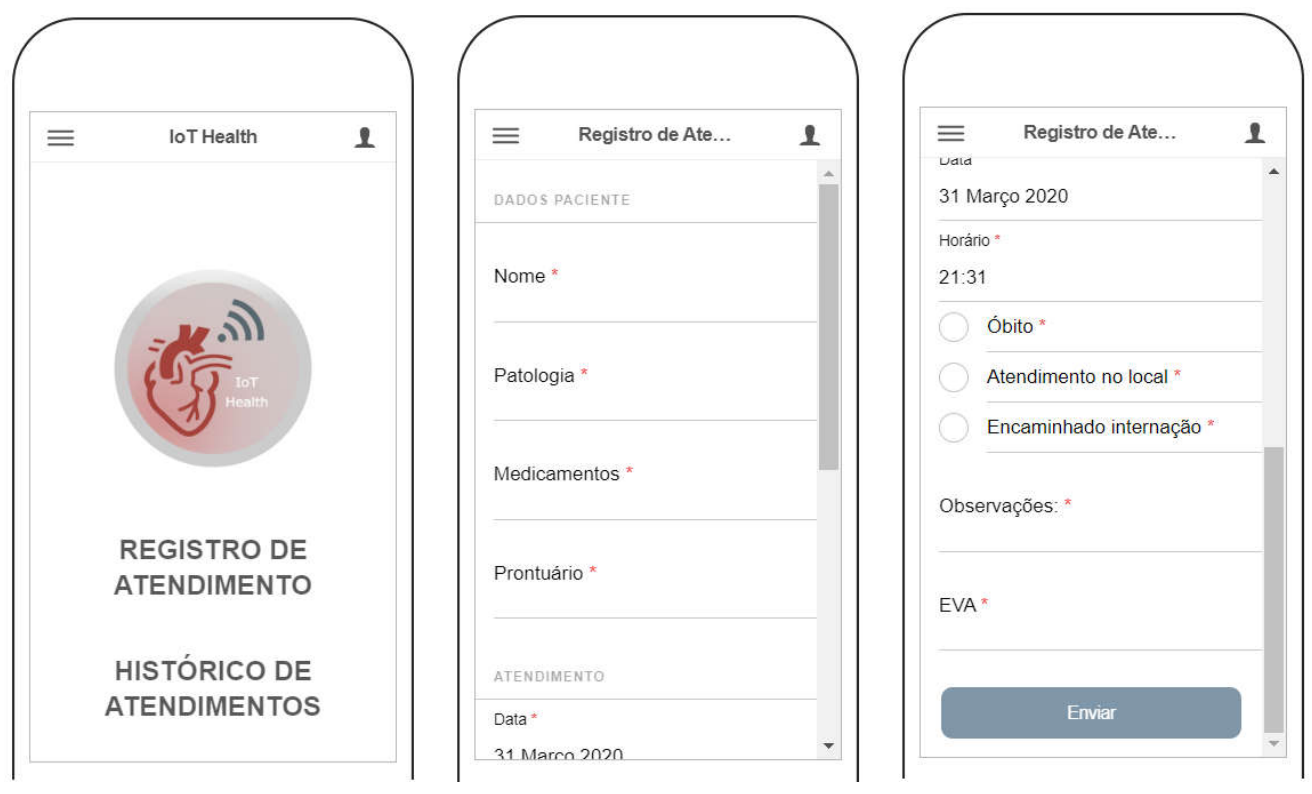

Source: Elaborated by the authors

It is important to mention that all those experiments utilized the digital data from the researchers involved in this effort. The hospital side is a replication of your real environment. The feedback from hospital personnel has been incredibly positive. However, the regulatory preconditions - as mentioned in Ricciardi et al (2019) - exist and are barriers to be surmounted.

\section{Conclusion and Future Works}

The actual Covid-19 pandemic scenario reinforces the necessary efforts, similar to the present research work, targeting the better use in the future of the digital transformation, big data, artificial intelligence and data analytics for healthcare. These technologies could accomplish the difference between poor digital data of today and information around the world about people's vital signals in the Covid-19 pandemic.

In this paper, we present an ongoing project, which targets the collection of vital signals digital data for public primary healthcare monitoring. Three fog environments were established with different types of people. The main goal of these classifications was to understand how difficult the procedures to get vital signals from these groups and storage in a public hospital are. The empirical experiments provide important lessons, because to have an expensive smart band does not represent the guarantee to access to the digital data by a third-party application. On one hand, low cost devices could provide access to personal data, but does not present the same features, such as level of battery life. These aspects are compatible with what we saw in the 
literature, which stated that innovations and new technologies could or could not materialize potential benefits. In addition, a personal education for all types of people is also required in this new digital transformation scenario.

Some future research actions (which are underway) are: (i) teaching the importance to gather digital data from vital signals to all groups involved in this research; (ii) a large effort to search for more appropriate smart bands in terms of cost-benefit; (iii) enhancements on the loT App to connect a set of mobile devices to the selected smart bands; (iv) implementing some procedures inside the fogs to data cleaning utilizing Al applications; and ( $v$ ) allowing some data analytics inside the fogs with the digital data collected.

Finally, it is important to highlight that the next steps of this research can provide a great contribution to minimizing the COVID-19 tests of the Brazilian population, which involves high costs, due to the size of the country. Tests can be minimized by monitoring individuals' specific vital signs, which include temperature, heart rate, oxygenation and blood pressure. More than costs, monitoring the individual health of each person, monitored by the smart bands of this proposal, allows faster actions by health professionals in patients with COVID-19 and others monitored due to their condition of comorbidities (for example, patients with cardiovascular, diabetic and hypertensive diseases). In other words, representing a monitoring approach could save lives and bring more security information inside environments to those who are required to work during the COVID-19 pandemic.

\section{Acknowledgment}

This research work of e-health was, partially supported, by the Brazilian National Research Council (CNPq), and the Fog-loT approach partially funded by TBE and EDP under supervision of ANEEL - The Brazilian Regulatory Agency of Electricity Project number PD-02651-0013/2017.

\section{References}

BHARADWAJ, A. et al. Digital business strategy: toward a next generation of insights. MIS Quarterly, Minneapolis, MN, USA, v. 37, n. 2, p. 471-482, 2013.

BIERZYNSKI, K.; ESCOBAR, A.; EBERL, M. Cloud, fog and edge: Cooperation for the future? In: Second International Conference on Fog and Mobile Edge Computing (FMEC), pp. 62-67, 2017. BRASIL. Lei No 13.989, de 16 de abril de 2020. Dispõe sobre o uso da telemedicina durante a crise causada pelo corona vírus (SARS-CoV-2). Disponível em: http://www.in.gov.br/web/dou//lei-n-13.989-de-15-de-abril-de-2020-252726328. Acesso em: 06 maio 2020. 
CENTER FOR DISEASE CONTROL AND PREVENTION - CDC (2019). 1918 Pandemic (H1N1 virus). Available in: <https://www.cdc.gov/flu/pandemic-resources/1918-pandemic-h1n1.html Accessed in May 2020.

CREMER, S.; LOEBBECK, C. Artificial Intelligence Imagery Analysis Fostering Big Data Analytics. In: Future Internet 2019, 11(8).

DANTAS, M. A. R.; BOGONI, P. E.; FILHO, P. J. F. An Application Study Case Tradeoff between Throughput and Latency on Fog-Cloud Cooperation. In: International Journal of Networking and Virtual Organization, vol. 23, No. 3, pp.247-260, 2020.

DU, J.; ZHAO, L.; FENG, J.; CHU, X. Computation Offloading and Resource Allocation in Mixed Fog/Cloud Computing Systems with Min-Max Fairness Guarantee. In: IEEE Transactions on Communications, vol. 66, No. 4, April 2018.

FITZGERALD, M. et al. Embracing digital technology: a new strategic imperative. Cambridge: MIT Sloan Management Review, 2013.

FLANNERY D.; JARRIN R. Building a regulatory and payment framework flexible enough to withstand technological progress. In Health Aff (Millwood) 2018; 37: 2052-9.

GOOGLE (2020). Available in: <https://ai.google/about/>. Accessed in April 2020.

IMPEDOVO, D.; PIRLO, G. eHealth and Artificial Intelligence. In: Information 2019, 10, 117.

INTERNATIONAL MONETARY FUND - IMF (2020). Available in:

$<$ https://www.imf.org/en/Topics/imf-and-covid19>. Accessed in May 2020.

LIBELIUM Comunicaciones Distribuidas - COOKING HACKS. E-health sensor platform v20 for arduino and raspberrypi [biometric/medical applications], 2014 [Online]. Available: https://www.cooking-hacks.com/documentation/tutorials/ehealth-biometric-sensor-platformarduino-raspberry-pi-medical.html. Accessed in May 2020.

KEESARA, S. M.D.; JONAS, A.M.D.; SCHULMAN, K.M.D. Covid-19 and Health Care's Digital Revolution. In: The New England Journal of Medicine. Downloaded from nejm.org on May 4, 2020.

NATIONS ONLINE (2020). Available in:

$<$ https://www.nationsonline.org/oneworld/first_world.htm>. Accessed in May 2020.

NAZARIO, D. C; CAMPOS, P. J.; INACIO, E. C.; DANTAS, M. A. R. Quality of Context Evaluating Approach: AAL Environment Using loT Technology. In: Computer Based Medical Systems (CBMS) 2017, pp. 558-563. 
ORACLE (2020). Available in: <https://www.oracle.com/big-data/what-is-big-data.html Accessed in May 2020.

PRICE WATERHOUSE HEALTH RESEARCH INSTITUTE (2020). Top health industry issues of 2020: will digital start to show an ROI? December 2019. Available in: $<$ https://www.pwc.com/us/en/industries/health-industries/assets/pwc-us-health-tophealth-issues.pdf>.

RAGHUPATHI, W.; RAGHUPATHI, V. Big data analytics in healthcare: promise and potential. In: Health Inf Sci Syst 2, 3 (2014). https://doi.org/10.1186/2047-2501-2-3

RICCIARDI, W.; BARRO, P. P.; BOUREK, A.; BROUWER, W.; KELSEY, T.; LEHTONEN, L. Expert Panel on Effective Ways of Investing in Health (EXPH), How to govern the digital transformation of health services, European Journal of Public Health, Volume 29, Issue Supplement_3, October 2019, Pages 7-12.

ROCHA T. A. H.; FACHINI L. A.; THUMÉ, E.; SILVA N. C; BARBOSA A. C. Q.; CARMO M.; RODRIGUES J. M. Saúde Móvel: novas perspectivas para a oferta de serviços em saúde. In: Epidemiol. Serv. Saúde, Brasília, 25(1):159-170, jan-mar 2016.

SANTOS, P.; MASSÓ, J. M. Rumo a uma nova realidade transformada. In: UNO - Desenvolvendo Ideias, São Paulo, n. 24. p. 29-30, 2016.

SAS Institute (2020). Available in: <https://www.sas.com/en_us/insights/analytics/what-isanalytics.html>. Accessed in May 2020.

SILVA, M. P.; GONÇALVES, A. L.; DANTAS, M. A. R. A conceptual model for quality of experience management to provide context-aware eHealth services. In: Future Gener. Comput. Syst. 101: 1041-1061 (2019).

SKORIN-KAPOV, L.; MATIJASEVIC, M. Analysis of QoS requirements for e-Health services and mapping to evolved packet system QoS classes. In: Int. J. Telemed. Appl. 2010 (2010) 628086, Published online 2010 Oct 7.

TAE, K. H.; ROH Y; OH, Y. H.; KIM, H.; WHANG, S. E. Data Cleaning for Accurate, Fair and Robust Models: A Big Data - Al Integration Approach. In: DEEM'19: Proceedings of the 3rd International Workshop on Data Management for End-to-End Machine Learning. June 2019 Article No.: 5 Pages 1-4.

TARDIEU, H.; DALY, D.; ESTEBAN-LAUZÁN, J.; HALL, J.; MILLER, G. Case Study 2: The Digital Transformation of Health Care. In: Deliberately Digital Future of Business and Finance. Springer, Cham: 2020. 
TOOLBOOM, I. The impact of digital transformation. $101 \mathrm{f}$. Master Thesis Report (Master in System Engineering, Policy analysis and Management) - Faculty of Technology, Policy and Management, Delf University of Technology, Delft, 2016.

WORLD ECONOMIC FORUM. World Economic Forum Annual Meeting, 2016.

WORLD HEALTH ORGANIZATION - WHO (2020). Available in

$<$ https://www.who.int/emergencies/diseases/novel-coronavirus-2019>. Accessed in May 2020.

WORLD HEALTH ORGANIZATION - WHO (2020). Coronavirus disease 2019 (COVID-19): situation report, 72 . Available in $<$ https://apps.who.int/iris/bitstream/handle/10665/331685/nCoVsitrep01Apr2020-eng.pdf>. Accessed in May 2020

XIAO, Y.; KRUNZ, M. QoE and Power Efficiency Tradeoff for Fog Computing Networks with Fog Node Cooperation. In: IEEE INFOCOM 2017 - IEEE Conference on Computer Communications, pp. 1-9, 2017.

ZARZALEJOS, J. A. Cidadania digital. In: UNO - Desenvolvendo Ideias, São Paulo, n. 24, p. 1113, 2016.

\section{Fabrício Martins Mendonça}

https://orcid.org/0000-0001-8156-8607

Adjunct Professor at Federal University of Juiz de Fora (UFJF), PhD in Information Science E-mail: fabricio.mendonca@ice.uffif.br

\section{Mário Antônio Ribeiro Dantas}

https://orcid.org/0000-0002-2313-7042

Full professor at Federal University of Juiz de Fora (UFJF), PhD in Computer Science, INESC P\&D Brazil.

E-mail: mario.dantas@ice.ufjf.br 